Chigrina Natalya, Head of neurological department of Stavropol Hospital of emergency, Tuhachevskogo, 17 , Stavropol, Russia, 355003

E-mail: chigrina.n@yandex.ru

Minaeva Olga, Candidate of Medical Sciences, associate professor, Department of neurology, neurosurgery and medical genetic, Stavropol State Medical University, Mira st., 310, Stavropol, Russia, 355003

Vishlova Irina, Candidate of Medical Sciences, assistant, Department of neurology, neurosurgery and medical genetic, Stavropol State Medical University, Mira st., 310, Stavropol, Russia, 355003

УДК 517:656:005.334

DOI: 10.15587/2313-8416.2015.37411

\title{
АНАЛИЗ ВЕДУЩИХ КОМПОНЕНТОВ ПРОИЗВОДСТВЕННОЙ СРЕДЫ ТРАНСПОРТНОЙ ОТРАСЛИ
}

\section{(C) Е. Н. Крекотень}

Проанализировано ведущие компоненты производственной среды (техника безопасности, условия труда, организационно-управленческая) трудящихся транспортной отрасли на предприятиях разньх форм собственности по результатам социологического опроса. Выявлена достоверная зависимость их распространенности от форм собственности предприятий, функционального назначения транспортных средств и региона пребывания

Ключевые слова: условия труда; техника безопасности; трудящчиеся; предприятия разных форм собственности

The reliability and efficacy of a man's working activity and his functional state much depend on structural features of the serviced equipment, technological processes and organization of production. From the advent of organizations of different types of ownership the issue of possible impact of this factor on the leading components of the manufacturing environment and the health of workers employed in this branch.

Aim. To learn and analyze of the leading components of the transport branch production environment that influence on a workers' health.

Methods and materials. According to the results of the public opinion poll the leading components of the production environment (safety engineering, working conditions and organizational) of workers of the transport branch at enterprises of different ownership forms have been analyzed. Sampled populations of the main and control groups were formed which analysis provided verification of the suggested hypotheses.

Results. The analysis of the leading manufacturing environment components of the transport branch has revealed significant dependence of their levels on the type of ownership of the enterprises, functional purpose of vehicles and location.

Conclusions. The comparative analysis was performed according to the criterion of the enterprise ownership form in two regions of the country. It has been established that worn-out and out-of-date equipment increases problems related to safety engineering manifold, makes working conditions worse increasing the risk of their influence on the health of people employed in the transport branch and the organization-management component considering bad managerial skills becomes an aggravating factor for the foregoing ones

Keywords: working condition; safety engineering; workers; enterprises of different ownership forms

\section{1. Введение}

Шестидесятая сессия Всемирной ассамблеи здравоохранения одобрила и утвердила Глобальный План Действий по здравоохранению трудящихся на 2008-2017 гг., в котором отмечено, что «....трудящиеся составляют половину населения мира и являются главным вкладчиком в экономическое и социальное развитие современного мирового сообщества. Их здоровье зависит от многих факторов производственной среды, социальных и поведенческих, а также от доступности медицинского обслуживания», и призвала державы мира разработать национальную политику и планы реализации ГПД на национальном уровне. Предложенный план действий касается всех аспектов здравоохранения трудящихся, включая первичную профилактику профессиональных вредностей, охрану и укрепление здоровья на рабочем месте, условия трудоустройства и более четкое реагирование систем здравоохранения на здоровье трудящихся [1].

\section{2. Постановка проблемы}

Надежность и эффективность трудовой деятельности человека, и его функциональное состояние во многом зависят от конструктивных особенностей 
обслуживаемой техники, технологических процессов и организации производства, то есть от того, насколько полно в конструкциях производственного оборудования и организации рабочих мест учтены современные требования эргономики [2, 3]. Несоблюдение этих требований приводит к ухудшению санитарно-гигиенических условий, увеличению тяжести труда, обусловленной выполнением производственной задачи в неудобной рабочей позе, большому количеству наклонов корпуса, слишком быстрому темпу, большой рабочей нагрузке и т. д., что особенно характерно для предприятий транспортной отрасли $[4,5]$. С появлением организаций разных форм собственности возникает вопрос о возможном влиянии этого фактора на ведущие компоненты производственной среды и здоровье трудящихся в данной отрасли.

\section{3. Литературный обзор}

Исследования оценки рисков на рабочем месте сравнительно с другими факторами, которые относятся к основным причинам смерти, занимают седьмое место после гипертензии, употребления алкоголя, некачественной питьевой воды, неполноценного питания, низкой физической активности, курения [6], тогда как среди показателей потенциальной потери жизни пятое, и второе - среди показателей лет жизни с неработоспособностью (после употребления алкоголя) [7].

В современный период в Украине причиной формирования профпатологии у трудящихся является свыше 200 вредных факторов, в т. ч. больше 20 видов пыли, а также таких физических факторов, как шум, вибрация, разные виды излучения и т. д. Их соотношение показывает, что на влияние от всех видов пыли приходится 58-67 \% пострадавших, вибрации -6-8\%, шума - 4-6 \%, всех химических веществ - 3-5\%, длительного статического напряжения - 5-6 \% [8].

По данным Большой Британии за 2004-2005 гг. в стране было зарегистрировано 23000 новых случаев болезней связанных с трудовой деятельностью [9]. Но, в отличие от подхода к проблеме в Украине, влияние условий труда на трудящихся учитывали через скрининговые программы на основании самооценки здоровья. За последний год по субъективной оценке 2,0 млн. людей считали себя больными или имели значительное ухудшение самочувствия, связанное с трудом, из них в 3/4 случая расстройства касались нарушений в костно-мышечной системе и соединительной ткани, а также стресса, депрессии и тревожности [8].

\section{4. Цель исследования}

Изучить и проанализировать ведущие компоненты производственной среды транспортной отрасли влияющие на здоровье трудящихся.

\section{5. Материалы и методы исследования}

Исследование проводилось на двух выборочных совокупностях (основная и контрольная группы) используя методологию социологического опроса респондентов в количестве 485 трудящихся (учтена количественная репрезентативность выборки) предприятий транспортной отрасли государственно-коммунальной и частной форм собственности. Предприятиями выбора состояли трамвайно-троллейбусные управления (кластер государственно-коммунальной формы собственности) и наземные транспортные перевозки (кластер частной формы собственности) - по одному предприятию каждой исследуемой группы и формы собственности, что в сумме составило четыре организации, как научные базы эпидемиологического поиска.

Предприятия частной формы собственности отличались по функциональному назначению транспортных средств, то есть, транспортные перевозки организации основной группы осуществлялись на дальние расстояния (в пределах страны и международные рейсы), тогда как в контрольной группе ограничивались территорией региона.

Разработана и апробирована анонимная анкета, вопросы которой структурированы в три блока: социально-экономический, производственный и образа жизни. Составлено и подписано информационное соглашение. Отказ от участия в исследовании составил $20 \%$, что не повлияло на достоверность данных и позволило экстраполировать результаты на генеральную совокупность.

Исследователем использованы следующие методы: эпидемиологический, социологический, статистический, системного подхода и анализа.

\section{6. Апробация результатов исследований}

Изучение проблем техники безопасности на предприятиях транспортной отрасли выявило основные их составляющие независимо от форм собственности и региона исследования. Произведена общая характеристика проблем техники безопасности без распределения по должностям. Выявлено, что наибольшей опасности на рабочем месте подвергаются трудящиеся физического (слесарь, столяр, газоэлектросварщик, шиномонтажник, сантехник и т. д.) и смешанного (водители) труда, опрос которых определил $100 \%$ их ознакомлённость с инструкцией по технике безопасности. При этом отсутствовало периодическое обучение респондентов о соблюдении правил техники безопасности, профилактики возникновения трудовых увечий и оказания первой медицинской помощи при экстренной необходимости, что указывает на высокий риск преждевременной смерти лиц трудоспособного возраста из-за несвоевременного оказания медицинской помощи (остановка кровопотери, предупреждение болевого шока и т. д.).

Определена статистически значимая разница выявленных проблем техники безопасности по форме собственности предприятий транспортной отрасли основной группы исследования (ответы респондентов предприятия государственно-коммунальной формы собственности к частной): падение - 60,1 $22,2 \%$ к 41,2 $\pm 5,7 \%(\mathrm{t}=3,09 ; \mathrm{p}<0,01)$; сварочные работы $14,9 \pm 1,6 \%$ к 41,2 $\pm 5,7 \%$ ( $=4,44 ; \mathrm{p}<0,01)$; подъемные работы - 18,0 $\pm 1,8 \%$ к 35,3 $\pm 5,5 \%(\mathrm{t}=3,0 ; \mathrm{p}<0,05)$; высокая

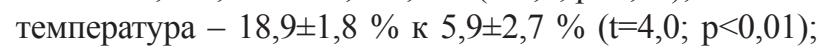
угроза пожара - 25,4 $2,0 \%$ к $14,7 \pm 4,1 \% \quad(\mathrm{t}=2,36$; $\mathrm{p}<0,05)$; поражение от падения предметов - 11,8 $\pm 1,5 \%$ к 41,2 $\pm 5,7 \%(\mathrm{t}=5,0 ; \mathrm{p}<0,01)$ соответственно. При этом 
каждый пятый участник $(22,1 \pm 1,9 \%)$ указал проблемой техники безопасности на своем рабочем месте низкую температуру независимо от формы собственности предприятия. Определено, что данный показатель статистически значимо ( $\mathrm{t} \geq 2,0 ; \mathrm{p}<0,05)$ выше в контрольной группе исследования как на предприятии государственно-коммунальной формы собственности $(36,4 \%)$, так и частной $(50,0 \%)$ по отношению к основной, что свидетельствует о более устаревших транспортных средствах в Житомирском регионе.

Это заключение подтверждает показатель подъёмных работ $18,0 \%$ респондентов государственнокоммунальной формы собственности предприятий Винницкого региона к 45,5 \% трудящихся предприятий Житомирского региона соответствующей формы собственности $(\mathrm{t}=3,4 ; \mathrm{p}<0,01)$, что говорит о частом проведении ремонтных работ устаревшей техники, а также более высокие показатели сварочных работ (27,3 \% участников контрольной группы к 14,9 \% лиц основной группы), высокой $(36,4 \%$ к 18,9\%; $\mathrm{t}=2,26$; $\mathrm{p}<0,05)$ и низкой $(36,4 \%$ к 21,5\%) температуры соответственно, что характерно для старых транспортных средств, не имеющих кондиционеров в летний период и проблемного изношенного неэкономичного отопительного оборудования в холодные времена года.

Существующая разница в показателях техники безопасности на предприятиях разных форм собственности обеих регионов обусловлена видом и функциональным назначением транспортных средств. Высокие показатели сварочных (41,2\%) и подъёмных $(35,3 \%)$ работ у лиц предприятий частной формы собственности связаны с транспортировкой товаров на большие расстояния, что приводит к быстрому износу и значительным повреждениям транспортного средства, учитывая состояние дорожного покрытия.
Анализ проблем техники безопасности на рабочем месте в зависимости от стажа работы выявил наибольшую проблему, во всех стажевых категориях, от падения (54-81 \%), с особенностями по группам: до 9,9 лет - от сварочных (29,6 \%) и подъёмных (31,8 \%) работ; от 10 до 25 лет и больше - низкая температура $(30,7$ \%) независимо от форм собственности предприятий и региона исследования.

Изучение второй ведущей компоненты производственной среды, влияющей на здоровье трудящихся - условий труда и вредных факторов, обозначило семь часто встречающихся факторов риска характерных для транспортной отрасли независимо от формы собственности предприятия и региона исследования (рис. 1).

Каждый второй респондент предприятий основной группы угрозой для здоровья отметил шум $(47,2 \pm 1,9 \%)$ и неудобное положение $(51,8 \pm 2,0 \%)$, тогда как на предприятиях контрольной группы эти показатели в 1,5 раза выше по шуму $(79,5$ \%) и незначительно ниже по второму фактору.

Существует статистически значимая разница по показателю шума между регионами $(\mathrm{t}=3,93 ; \mathrm{p}<0,01)$, при ее отсутствии по форме собственности предприятия.

Вредное влияние вибрации указал каждый третий $(32,8 \pm 1,8 \%)$ участник основной группы независимо от формы собственности предприятий, при его увеличении в два раза $(67,7$ \%) у трудящихся контрольной группы. Определена статистически значимая разница данного показателя по регионам: $36,6 \pm 1,8$ \% лиц основной к 64,7 $\pm 7,5 \%$ респондентов контрольной группы $(\mathrm{t}=3,66 ; \mathrm{p}<0,01)$ предприятий государственно-коммунальной формы собственности и $31,3 \pm 2,9 \%$

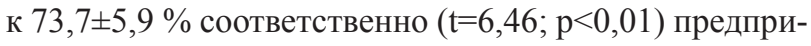
ятий частной формы собственности.

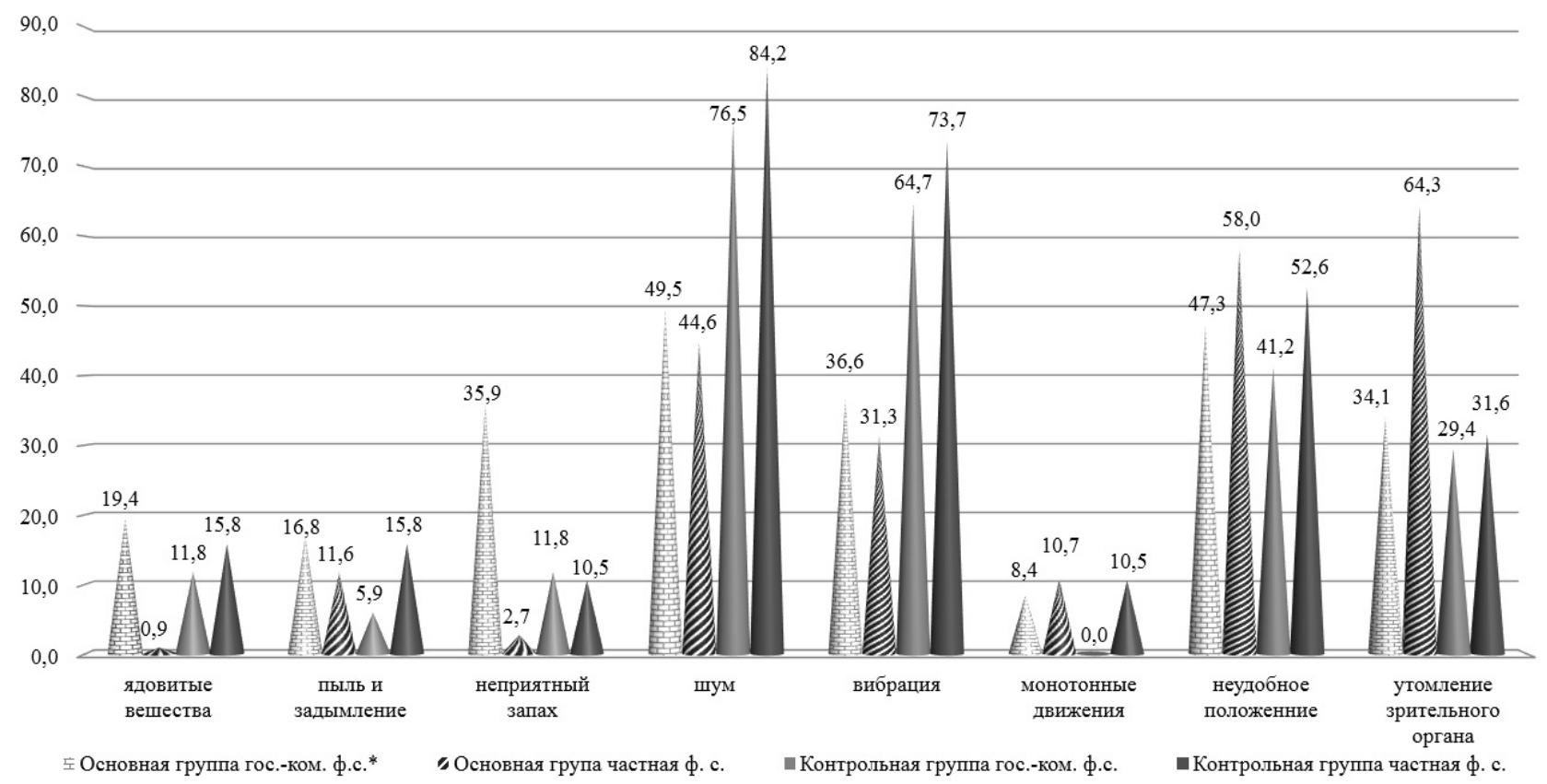

Рис. 1. Сравнительная характеристика условий труда на предприятиях транспортной отрасли разных форм собственности по группам исследования (основная; контрольная) на 100 трудящихся

Примечание: * государственно-коммунальная форма собственности 
Утомление зрительного органа отметили $34,1 \pm 1,8 \%$ респондента предприятий государственно-коммунальной формы собственности к 64,3 $\pm 3,0$ \% лиц предприятий частной формы собственности Винницкого региона $(\mathrm{t}=8,64 ; \mathrm{p}<0,01)$ и $29,4 \%$ к $31,6 \%$ соответственно Житомирского региона. Выявлена достоверно значимая разница $(\mathrm{t}=4,74 ; \mathrm{p}<0,01)$ приведённого показателя между группами исследования предприятий частной формы собственности двух регионов.

Три последующих фактора риска, влияющих на здоровье трудящихся предприятий транспортной отрасли, значимо разнились по форме собственности предприятий основной группы, при отсутствии таковой в контрольной.

Определено, что $19,4 \pm 1,5$ \% трудящихся предприятий государственно-коммунальной формы собственности к $0,9 \%$ респондентов предприятий частной форм собственности Винницкого региона перебывали в контакте с ядовитыми веществами $(\mathrm{t}=11,64 ; \mathrm{p}<0,01)$; пыль и задымление отметили $16,8 \pm 1,4 \%$ к 11,6\% участников $(\mathrm{t}=2,14 ; \mathrm{p}<0,05)$; неприятный запах $35,9 \pm$ $\pm 1,8 \%$ к $2,7 \%$ лиц ( $\mathrm{t}=16,13 ; \mathrm{p}<0,01)$ соответственно.

Подтверждено существование достоверной разницы по изучаемым группам исследования: пыль и задымление - 16,8 \% трудящихся основной группы к 5,9\% исследуемых контрольной предприятий государственно-коммунальной формы собственности; неприятный запах $-35,9 \%$ к 11,8 \% соответственно и ядовитые вещества - 0,9\% респондентов Винницкого региона к 15,8 \% участников Житомирского региона предприятий частной формы собственности.

Углубленный анализ показателей условий труда приводит к выводу о достоверном влиянии формы собственности предприятия на эту компоненту производственной среды транспортной отрасли и дополняет утверждение автора о стареющих, изношенных транспортных средствах работающих на территории Украины и за ее пределами, негативное влияние которых проявляется в трехмерном измерении - окружающая среда, здоровье трудящихся и безопасность транспортного средства.

Изучение зависимости указанных условий труда от стажа роботы установило, что до показателей шума, вибрации и неудобного положения в стажевой группе до 9,9 лет присоединился показатель «влияние ядовитых веществ» (28 \%), тогда как после 20 лет работы отмечен высокий показатель «утомление зрительного органа» (54 \%), что соответствует данным литературных источников и подтверждает выдвинутую нами гипотезу. Статистически значимой разницы по форме собственности предприятий и региона исследования не выявлено.

Респондентами выделены организационноуправленческие проблемы, влияющие на качество работы, психологическое состояние трудящихся и их трудоспособность. Определена зависимость данного критерия от формы собственности предприятий, групп исследования и функционального назначения транспортных средств.
Каждого второго $(48,1 \pm 2,4 \%)$ респондента основной и каждого третьего $(31,3 \pm 2,8 \%)$ контрольной группы предприятий государственно-коммунальной формы собственности неудовлетворял проект рабочего места, тогда как у предприятий частной формы собственности этот показатель составил 3,3 \% и 23,1\% соответственно, при статистически значимой разнице между группами $\mathrm{t}=2,1 ; \mathrm{p}<0,05$.

Сравнительная характеристика показателей организационно-управленческой составляющей трудящихся предприятий транспортной отрасли разных форм собственности основной группы предопределила пять проблем с достоверной разницей $\mathrm{t}=6,0 ; \mathrm{p}<0,01$ :

- перегрузка работой $-41,0 \pm 2,4$ \% лиц предприятий государственно-коммунальной формы собственности к 9,8 \% участников предприятий частной фор-

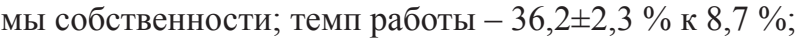

- длительная продолжительность рабочего дня $-16,7 \pm 1,8 \%$ к $88,0 \%$;

- перерывы на отдых - 14,8 1 1,7 \% к 2,2 \%;

- санитарные условия - 17,6 $\pm 1,8 \%$ к $2,2 \%$ сон ответственно.

При этом указанная особенность не подтвердилась в контрольной группе за исключением показателя «перегрузка работой», который отметили 12,5 \% респондентов предприятий государственно-коммунальной формы собственности к 61,5 \% трудящихся предприятий частной формы собственности, а показатель «длительная продолжительность рабочего дня» имел обратную связь - 56,3 \% к 7,7 \% соответственно, что подтверждает возникновение организационных проблем в зависимости от функционального назначения транспортных средств, которые описано в разделе «материалы и методы исследования».

Каждый четвертый участник исследования контрольной группы отметил проблемой монотонную работу, что в основной группе составило 16,2\%, а каждый третий (31,3\%) трудящийся предприятия государственно-коммунальной формы собственности контрольной группы назвал неудовлетворительные санитарные условия, что на предприятии частной формы собственности в два раза ниже $(15,4$ \%). Выявлена статистически значимая разница $(\mathrm{t}=4,78 ; \mathrm{p}<0,01)$ между предприятиями контрольной группы по показателю «сменная работа» - 43,8 \% респондентов предприятий государственно-коммунальной формы собственности к 7,7 \% лиц предприятий частной формы собственности, который имел достоверную разницу и между предприятий государственно-коммунальной формы собственности регионов - 43,8 \% участников Житомирского к 1,9 \% лиц Винницкого региона ( $\mathrm{t}=4,9$; $\mathrm{p}<0,01)$, не имея таковой по предприятиях частной формы собственности.

Важным результирующим аспектом изучения компонентов производственной среды при проведении научного поиска предусмотрено изучение субъективных жалоб на состояние здоровья трудящихся транспортной отрасли при осуществлении трудовой деятельности независимо от возраста и стажа работы. 
Определенно, что 438 (80-92\%) респондентов отметили усталость, каждый второй имел кашель (46,3 \%), что коррелировало с показателями «курение» и «пол» $(\mathrm{r}=+0,84$ и $\mathrm{r}=+0,72$ соответственно), а также «боль в спине» $(49,5 \%)$.

Выявлена статистически значимая разница между предприятиями разной формы собственности основной группы по показателям:

- «боль в глазах» - 24,1 $2,4 \%$ респондентов предприятий государственно-коммунальной формы собственности к $61,4 \pm 4,3$ \% лиц предприятий частной формы собственности;

- «высокое артериальное давление» - 52,4士 $\pm 2,9 \%$ к $13,4 \%$;

- «раздражение кожи» - 7,8 \% к 27,2 \%;

- «боль в спине» - 65, $1 \pm 2,7 \%$ к 8,2 \%;

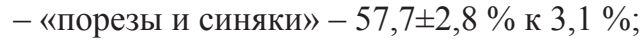

- «желудочные проблемы» - 36,5 2 , 7 \% к 3,9\% соответственно, определяющих влияние форм собственности предприятий на состояние здоровья трудящихся.

Групповая достоверная разница наблюдалась по показателям: «стресс» - 27,2 2,1 \% респонден-

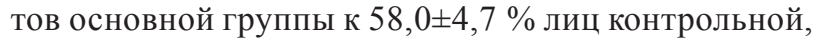
учитывая его увеличение в два раза между предприятиями разных форм собственности - 27,7 \% участников основной к 56,0 \% лиц контрольной группы предприятий государственно-коммунальной формы собственности и $26,0 \%$ к $60,0 \%$ соответственно респондентов предприятий частной формы собственности, что указывает на значительно устаревшее, изношенное техническое оборудование и транспортные средства на предприятиях данной отрасли, приводящих к психологической нагрузке соответствующей категории населения. Это подтверждают и показатели «порезов и синяков» обеих исследуемых групп - каждый третий $(30,0 \%)$ участник контрольной группы и 41,7 \% респондентов предприятий основной группы, а также «кашель», который косвенно зависел от стресса, создавая порочный круг - стресс $\rightarrow$ курение $\rightarrow$ кашель, особенно у трудящихся предприятий частной формы собственности (30-60\%), имеющих множество вмешивающихся факторов влияния на показатель стресса.

Автором выявлена и доказана зависимость ведущих компонентов производственной среды (техники безопасности, условий труда, организационноуправленческой) предприятий транспортной отрасли от форм собственности, экономического и технического обеспечения организаций.

\section{6. Выводы}

1. Анализ ведущих компонентов производственной среды транспортной отрасли выявил достоверную зависимость их распространенности от форм собственности предприятий, функционального назначения транспортных средств и региона пребывания.

2. Выявлено, что изношенная и устаревшая техника (оборудование, транспортные средства) в разы увеличивает проблемы, связанные с техникой безопасности, ухудшает условия труда, повышая риск их влияния на здоровье трудящихся транспортной отрасли, а организационно-управленческая компонента, при низких менеджерских способностях, становится усугубляющим фактором к указанным двум.

3. Отсутствие образовательных программ по технике безопасности, использовании индивидуальных средств защиты на рабочем месте, профилактики профессиональных заболеваний и трудовых увечий оценена как неудовлетворительная работа управленческого аппарата предприятий независимо от формы собственности и региона исследования, приводящие к экономическому и демографическому ущербу страны, в связи с потерями трудоспособного населения, особенно лиц мужского пола, преобладающего в данной отрасли.

\section{Литература}

1. Измеров, Н. Ф. Глобальный план действий по охране здоровья работающих на 2008-2017 гг.: пути и перспективы реализации [Текст] / Н. Ф. Измеров // Медицина труда и промышленная экология. - 2008. - № 6. - С. 1-9.

2. Матюхин, В. В. Факторы риска в развитии функциональных нарушений у работников физического труда [Текст] / В. В. Матюхин, В. В. Елизарова, Э. Ф. Шардакова, Е. Г. Ямпольская // Медицина труда и промышленная экология. -2009 . - № 6. - С. 1-6.

3. Цуркан, В. Механізм формування якісного виробничого середовища [Текст] / В. Цуркан // СЕС, профілактична медицина. - 2011. - № 1. - С. 24-25.

4. Anderson, V. P. Occupational fatalities, injuries, illnesses and related economic loss in the wholesale and retail trade sector [Text] / V. P. Anderson, P. A. Schule, J. Sestito // American Journal of Industrial Medicine. - 2010. - Vol. 53, Issue 7. - P. 673-685. doi: 10.1002/ajim.20813

5. Czapka, M. legal and economic consequences of the accidents at work and occupational diseases in France [Текст] / M. Czapka, U. Kontny // Український журнал з проблем медицини праці. - 2011. - № 2. - С. 68-77.

6. Кундієв, Ю. І. Професійне здоров'я в Україні. Епідеміологічний аналіз [Текст] / Ю. І. Кундієв, А. М. Нагорна - К.: Авіцена, 2007. - 396 с.

7. Occupational Safety and Health Statistics Bulletin [Electronic resource] / 2013. - Available at: http://www.labour. gov.hk/eng/osh/pdf/Bulletin2012.pdf

8. Кундієв, Ю. І Стратегія забезпечення безпечних умов праці і збереження здоров'я працюючих в Україні на 2006-2010 роки [Текст] / Ю. І. Кундієв, А. М. Нагорна, В. І. Чернюк // Укр. журн. 3 пробл. медицини праці. - 2005. № 3-4. - C. 4-10.

9. World Health Organization () Global Health Observatory Data Repository [Electronic resource] / 2013. - Available at: http://apps.who.int/gho/data/view/main

\section{References}

1. Yzmerov, N. F. (2008). Hlobal'nыy plan deystvyy po okhrane zdorov'ya rabotayushchykh na 2008-2017 hh.: puty y perspektyvы realyzatsyy [Global plan of operating under a health care workings on 2008-2017 yy. : ways and prospects of realization]. Medytsyna truda y promishlennaya эkolohyya, 6, 1-9.

2. Matyukhyn, V. V., Elyzarova, V. V., Shardakova, E. F., Yampol'skaya, E. H. (2009). Faktori ryska v razvytyy funktsyonal'nikh narushenyy u rabotnykov fyzycheskoho truda [Risk factors in development of functional violations for the 
workers of manual labour]. Medytsyna truda y promishlennaya эkolohyya, 6, 1-6.

3. Tsurkan, V. (2011). Mekhanizm formuvannya yakisnoho vyrobnychoho seredovyshcha [Mechanism of forming of high-quality production environment]. Sanitarno-epidemiolohichna sluzhba, 1, 24-25.

4. Anderson, V. P., Schule, P. A., Sestito, J. (2010). Occupational fatalities, injuries, illnesses and related economic loss in the wholesale and retail trade sector. American Journal of Industrial Medicine, 53 (7), 673-685. doi: 10.1002/ajim.20813

5. Czapka, M., Kontny, U. (2011). Legal and economic consequences of the accidents at work and occupational diseases in France. Ukrayins'kyy zhurnal z problem medytsyny pratsi, 2, 68-77.
6. Kundiyev, Yu. I., Nahorna, A. M. (2007). Profesiyne zdorov"ya v Ukrayini. Epidemiolohichnyy analiz [A professional health in Ukraine]. Kiev: Avitsena, 396.

7. Occupational Safety and Health Statistics Bulletin (2013). Available at: http://www.labour.gov.hk/eng/osh/ pdf/Bulletin2012.pdf

8. Kundiyev, Yu. I., Nahorna, A. M., Chernyuk, V. I. (2005). Stratehiya zabezpechennya bezpechnykh umov pratsi i zberezhennya zdorov"ya pratsyuyuchykh v Ukrayini na 2006-2010 roky [Strategy of providing of safe terms of labour and saving of health of workings is in Ukraine on 2006-2010 yy.]. Ukr. zhurn. z probl. medytsyny pratsi, 3/4, 4-10.

9. World Health Organization (2013). Global health observatory Data Repository. Available at: http://apps. who.int/gho/data/view/main

Рекомендовано до публікації д-р мед. наук, професор Очередько О. М. Дата надходження рукопису 09.01.2015

Крекотень Елена Николаевна, кандидат медицинских наук, доцент, кафедра социальной медицины и организации здравоохранения, Винницкий национальный медицинский университет имени Н. И. Пирогова, ул. Пирогова, 56, г. Винница, Украина, 21018

E-mail: olena1977@mail.ru

\title{
УДК 616.22-077.271;612.521.2;616-072.1-089-001.8 \\ DOI: $10.15587 / 2313-8416.2015 .37408$
}

\section{АНЕСТЕЗІОЛОГІЧНЕ ЗАБЕЗПЕЧЕННЯ ЕНДОСКОПІЧНИХ МІКРОХІРУРГІЧНИХ ВТРУЧАНЬ 3 ПРИВОДУ ПАРАЛІТИЧНОГО СТЕНОЗУ ГОРТАНІ}

\author{
() Д. О. Покришень, С. О. Дубров
}

Хірургічні втручання з приводу паралітичного стенозу гортані вважаються одними з найскладніших 8 мікрохірургії гортані. В даній роботі обговорюються різні методи вентилячії легень, які можуть бути застосовані під час ендоскопічних втручань з приводу паралітичного стенозу гортані та подається аналіз їх впливу на результати хірургічного лікування даної патології

Ключові слова: паралітичний стеноз гортані, струминна вентиляція легень, мікрохірургія гортані, трахеостомія

Surgical repair of bilateral vocal cord paralysis is widely considered as one of the most complicated procedures in laryngeal microsurgery. Unobstructed view of laryngeal structures and adequate amount of working space are essential prerequisites for successful microsurgical operation. In order to provide necessary surgical condition several ventilatory techniques can be employed. Available options include preventive tracheostomy, conventional ventilation via small endotracheal tubes and jet ventilation. At the same time, improvement of surgeons'working conditions is never considered as an ultimate goal if it does not lead to better results or decrease of expenses.

Materials and methods. We report a retrospective study of 104 patients who had undergone microlaryngeal surgery for bilateral vocal cord paralysis. Duration of hospital stay, duration of surgery and time spent in the operating room were compared between the three groups of patients with different ventilation strategies.

Results. The highest duration of hospital stay was in the group of preventive tracheostomy (18,68土7,48 days), whereas in the groups of tracheal intubation and subglottic jet ventilation it was considerably lower $(12,9 \pm 7,11$ and 12,15 $\pm 5,69$ respectively).

Conclusions. Obtained data suggest that preventive tracheostomy performed prior to endoscopic microlaryngeal surgery is the major independent risk factor of prolonged hospital stay for patients with bilateral vocal cord paralysis

Keywords: bilateral vocal cord paralysis, laryngeal microsurgery, jet ventilation, tracheostomy

\section{1. Вступ}

Двобічний параліч голосових зв'язок на сьогоднішній день становить значну медико-соціальну проблему. Розлади, які виникають при цій патології, призводять до інвалідизації пацієнтів внаслідок порушення зовнішнього дихання i, часто, при розвитку 